\title{
Ser alguém na vida: um estudo sobre jovens do meio rural e seus projetos de vida'
}

Maria Zenaide Alves"

Juarez Dayrel|"II

\section{Resumo}

Este artigo discute as categorias juventude e projetos de vida, abordando-as a partir de uma pesquisa qualitativa realizada com jovens moradores da zona rural. 0 objetivo é problematizar a categoria projetos de vida, tomando como referência empírica um grupo de sujeitos de um município mineiro e refletindo sobre a importância dessa categoria para as discussões contemporâneas acerca da juventude. 0 estudo foi realizado com estudantes do ensino médio, moradores de uma região brasileira marcada pela cultura da migração e cujos projetos de vida mostraram-se sob pontos de vista distintos. A noção de projetos de vida é utiliza neste trabalho em uma perspectiva ampla, não se limitando às escolhas profıssionais. Isso porque falar em projetos de vida não pode se limitar a falar em profissão. Afinal, a vida não se resume a trabalho. Para definir e caracterizar os projetos de vida do grupo pesquisado, lançou-se mão de algumas categorias analíticas discutidas a partir de: um arcabouço teórico acerca das noções de juventude, projetos de vida e campo de possibilidades; e das evidências empíricas captadas por meio do estudo etnográfico realizado. A pesquisa concluiu que, embora sejam distintos os modos como os jovens organizam suas condutas futuras, o desejo de "ser alguém na vida" é uma orientação comum à maioria dos sujeitos investigados.

\section{Palavras-chave}

Juventude - Projetos de vida - Ser alguém na vida.

I- Pesquisa desenvolvida com apoio do Conselho Nacional de Desenvolvimento Científico e Tecnológico (CNPq) e da Coordenação de Aperfeiçoamento de Pessoal de Nível Superior (Capes).

II- Universidade Federal de Goiás, Catalão, GO, Brasil.

Contato: zenpiaui@yahoo.com.br

III- Universidade Federal de Minas Gerais, Belo Horizonte, MG, Brasil.

Contato: juareztd@gmail.com 


\title{
Being someone in life: a study on rural young people and their life projects
}

Maria Zenaide Alves'

Juarez Dayrell"

\begin{abstract}
This article discusses the categories youth and life projects. Its main goal is to question the category life projects, based on a qualitative study with a group of young people from a rural municipality of Minas Gerais state and reflecting about the importance of this category to the contemporary discussion on youth. The study was conducted with high school students, residents of a Brazilian region marked by the culture of migration and whose life projects evidenced from different points of view. The concept of life projects is used in this article in a broad perspective, not limited to professional choices, because life projects cannot be limited to career; after all, life is not work only. To define and characterize the life projects of the subjects, some analytical categories have been discussed and analyzed using a theoretical framework about the notions of youth, life projects, and field of possibilities using and empirical evidence of the ethnographic study performed. The research concluded that, although young people had different ways of organizing their life projects, most of them shared the desire to be someone in life.
\end{abstract}

\section{Keywords}

Youth - Life projects - Being someone in life.

I- Universidade Federal de Goiás, Catalão, GO, Brasil.

Contact: zenpiaui@yahoo.com.br

II- Universidade Federal de Minas Gerais,

Belo Horizonte, MG, Brasil.

Contact: juareztd@gmail.com 


\section{Enunciando questões}

"0 que você quer ser quando crescer?" Quem nunca fez essa pergunta ou foi indagado a esse respeito na infância ou na adolescência? Provavelmente quem a faz está se referindo à vida adulta na sua dimensão profissional, ou seja, quer saber que profissão a pessoa pretende exercer quando entrar no mercado de trabalho. A dimensão profissional é importante e tem um lugar privilegiado na discussão sobre o tema tratado aqui - projetos de vida -, mas não é suficiente para abordar o assunto. Isso porque falar em projetos de vida não pode se limitar a falar em profissão. Afınal, a vida não se resume a trabalho. Falar em projetos de vida é mais amplo, porque, além da vida profissional, também é preciso problematizar outras dimensões da condição humana, como as escolhas afetivas, os projetos coletivos e as orientações subjetivas da vida individual.

Partindo dessa problemática, o objetivo deste artigo é discutir a categoria projetos de vida, tomando como referência empírica um grupo de jovens moradores da zona rural, e refletindo sobre a importância dessa categoria para as discussões contemporâneas acerca da juventude. A análise aqui proposta é fruto de uma pesquisa (ALVES, 2013) que investigou os modos como um grupo de jovens moradores da zona rural, estudantes do ensino médio, pensa e organiza suas condutas futuras, aqui chamadas de projetos de vida. A investigação foi desenvolvida entre 2009 e 2013 e os dados empíricos aqui analisados foram coletados durante pesquisa de campo realizada entre setembro de 2010 e junho de 2011. Tratou-se de uma pesquisa etnográfica e a observação participante foi o instrumento privilegiado de coleta de dados. Também se utilizaram questionários, aplicados a todos os jovens estudantes de ensino médio da escola na etapa inicial da pesquisa de campo, e entrevistas individuais e coletivas, conduzidas nos meses finais da pesquisa com um grupo de jovens informantes centrais desta investigação.
0 estudo foi realizado em um município mineiro localizado em uma região marcada pelas migrações internacionais, de acordo com Margolis (1994), Fusco (2000), Soares (2002), Siqueira (2006), dentre outros, a qual guarda, assim, fortes características do que Massey et al. (1993) denominam "cultura da migração”. Esse município - São Geraldo da Piedade (SGP) - é entendido neste trabalho como rural, nos termos de José Eli da Veiga (2003). A investigação foi desenvolvida com jovens estudantes da única escola de ensino médio da cidade. No ano letivo de 2010, estavam matriculados 306 estudantes nesse nível de ensino, dos quais 195 responderam ao questionário inicial da pesquisa. Apesar da presença de adultos matriculados - uma necessidade, já que o município não oferecia a modalidade EJA -, os estudantes em idade regular (15 a 17 anos) eram maioria no grupo, perfazendo um total de $66,7 \%$ das matrículas, acima da média nacional, que era de 50,9\%, de acordo com o Instituto de Pesquisa Econômica Aplicada (IPEA, 2010). Esses estudantes eram majoritariamente moradores da zona rural do município (79\% dos matriculados). Quanto à constituição familiar, 93,8\% eram solteiros e apenas 2,6\% tinham filhos. Sobre identidade étnico-racial, de acordo com as categorias adotadas pelo Instituto Brasileiro de Geografia e Estatística (IBGE), 63,6\% se autodeclaram pardos, $16,4 \%$ pretos, $11,3 \%$ brancos, $6,2 \%$ amarelos e 2,1\% indígenas.

\section{Definindo a categoria projetos de vida}

As bases teóricas utilizadas neste estudo para discutir a categoria projetos de vida estão assentes sobretudo em Boutinet (2002), Velho (2003; 2004) e Machado (2004). De acordo com Boutinet (2002), o conceito de projeto tem raizes na arquitetura, mas ganha lugar de destaque nas produções filosóficas na primeira metade do século XX, embasado na ideia de intencionalidade e justificado na capacidade de 
devir dos seres humanos. Nesse mesmo sentido, Machado (2004) assume que nós, seres humanos, alimentamo-nos dos projetos que realizamos. É isso que nos permite fugir aos determinismos e improvisos, organizando e planejando nossas ações futuras. Esse processo não é linear tampouco singular. Ou seja, realizamos projetos diversos simultaneamente e o fazemos em movimentos de ida e volta, de avaliação e reavaliação das nossas ações, orientando-nos por metas que foram atingidas (ou não) e por perguntas que foram respondidas (ou não).

Para Machado (2004), projeto está diretamente relacionado a valores. Assim, um sujeito, em uma determinada sociedade e tempo histórico, desenvolve projetos fundamentados nos valores que orientam seus modos de ver o mundo. Por exemplo, um projeto de lei (que, depois de analisado e aprovado, torna-se legislação) que embasa a educação nacional de um país carrega os valores que orientam essa sociedade e os ideais de sujeito que esta pretende formar.

Da mesma forma, os projetos de vida são carregados de valores, tanto individuais quanto dos grupos sociais nos quais vivemos. Esse autor aponta outra característica essencial para o entendimento dessa categoria, que é o caráter indelegável e intransferível da ação projetada, alertando que "não se pode projetar pelos outros" (MACHAD0, 2004, p. 7). 0 entendimento dessa dimensão é fundamental, sobretudo no que tange aos projetos individuais ou de grupos, no sentido de que, por exemplo, os pais não podem (ou pelo menos não deveriam) projetar pelos filhos, como também os professores não podem (ou não deveriam) projetar por seus alunos.

Boutinet define projeto como uma antecipação justificada em experiências prévias, argumentando que:

Um grande número das realizações que concretizam a experiência humana são anteriormente interiorizadas, refletidas, antecipadas e orientadas pelo mecanismo do projeto. Este evitará que o indivíduo se deleite na compulsão da repetição, esforçando-se para criar o inédito, um inédito que mantenha um secreto parentesco com a experiência já realizada do indivíduo, com sua história pessoal. É esse parentesco, essa conivência não confessa porque dificilmente observável - que dará significação ao projeto. (2002, p. 270).

Nesse sentido, entende-se que os projetos de vida baseiam-se na biografia, na história de vida dos sujeitos, embora não se queira com isso tomá-los como um círculo vicioso ao qual os sujeitos estariam condicionados por suas biografias. Trata-se de uma dinâmica que está intimamente ligada à construção da identidade, que, segundo Dayrell (1999), é um processo de aprendizagem que implica o amadurecimento da capacidade de integrar o passado, o presente e o futuro, bem como as condições objetivas e subjetivas, e que articula a unidade e a continuidade de uma biografia individual. Para Velho (2003), é um processo “dinâmico e permanentemente reelaborado, reorganizando a memória do ator, dando novos sentidos e significados, provocando com isso repercussões nas suas identidades" (p. 104).

A construção da identidade e o descobrimento do eu é fruto de um percurso que não está dado, como nos alerta Dayrell (1999), e que também não acontece, de acordo com Spranger (1970), pacificamente. Ao contrário, manifesta-se de forma antagônica, em um movimento que é tanto da fuga de si próprio como da busca de respostas à pergunta “quem sou eu?". É também um movimento do despertar, por parte dos jovens, de outros interesses, diferentes daqueles da infância, em virtude das transformações psíquicas pelas quais estão passando. É aí que emerge um impulso por independência e o desejo por emanciapação em relação ao mundo adulto, o qual leva o sujeito à necessidade de fazer planos ou de ter projetos. Nesse sentido, o que ser ou fazer no futuro é uma questão que, a partir de um determinado momento, para uns mais 
cedo, para outros mais tarde, passa a compor o universo de preocupações dos jovens.

\section{O campo de possibilidades e as dimensões subjetivas}

Os projetos de vida são elaborados tendo como referência a biografia, como já mencionado, e o campo de possibilidades. Essa categoria tem sido por nós utilizada, com base no entendimento do sociólogo Gilberto Velho (2003), para dizer das alternativas que podem ser sonhadas e desejadas, individual ou coletivamente, no contexto sociocultural no qual os sujeitos estão inseridos. Para Velho, a realização do projeto se consubstancia através da identidade e do conhecimento da realidade na qual o sujeito vive e, ainda, dos meios de que dispõe para garantir sua sobrevivência, no que o autor define como "o espaço para formulação e implementação de projetos” (p. 40).

Para os jovens desta investigação, por exemplo, no contexto no qual estavam crescendo, a migração (seja para estudar, seja para trabalhar ou simplesmente por um desejo de deixar a vida no campo) era o que mais estava posto no campo de possibilidades após o término do ensino médio. Todavia, dado que o campo de possibilidades não é determinista e dialoga com as condições subjetivas do sujeito, nem sempre tal projeto era possível de se concretizar. Primeiro, porque migrar não depende exclusivamente do desejo ou mesmo de viver em um contexto de cultura da migração. Não migra quem quer; migra quem pode, quem reúne as condições (em geral econômicas, mas não só) necessárias para tal. Mesmo para os projetos de migração irregular, em que a condição financeira é um dos aspectos decisivos, o indivíduo precisa reunir disposição pessoal para se submeter a todas as adversidades da empreitada.

Em termos profissionais, ser policial era o sonho mais presente, seguido do desejo de ser médico. Embora neste estudo não se tenha dedicado atenção para detalhar o porquê das escolhas, algumas hipóteses podem ser aventadas sobre o motivo desse desejo de ser policial. Sendo esta uma das figuras públicas mais influentes e respeitadas no local - que, ao lado do padre e do prefeito, constituem os três poderes de SGP -, esse pode ser um caminho para esses jovens conquistarem o reconhecimento que tanto almejam. Outra hipótese é que eles, além de serem influenciados pelo poder que significaria essa profissão, podem avaliar que esta lhes seja um ofício de mais fácil acesso (já que não exige nível superior) e com rentabilidade que eles consideram justa. A profissão de policial ocupa uma posição oposta à de professor nos projetos dos jovens. Esta é considerada por eles sem prestígio, sem reconhecimento e sem retorno financeiro e é, portanto, rechaçada.

Uma alternativa que os jovens (sobretudo as meninas) veem como muito forte no seu campo de possibilidades tem relação com os projetos afetivos e financeiros. A maioria falava do não desejo de ver reproduzidas em suas vidas situações que têm dentro de casa, como o casamento e a dependência financeira do marido, o que levava algumas a negar em seus projetos de vida, mesmo em um futuro distante, o casamento, a vida de dona de casa, de mãe de família. Para algumas dessas jovens, isso seria uma condenação a uma vida sem graça, sem perspectivas de futuro, sem autonomia. Para outras, casamento e filhos aparecem nos projetos, mas somente depois que conseguirem se realizar profissionalmente.

Outra questão social que afeta aquela pequena comunidade - que, portanto, está no campo de possibilidades - e que os jovens analisam quando falam dos seus projetos de vida é a dependência de drogas, lícitas e ilícitas. 0 consumo de bebida alcóolica por meninos e meninas, para alguns desde a adolescência, é bastante comum na Cidade pesquisada. Isso os faz perceber o perigo da dependência de e do envolvimento com drogas, sobretudo, as ilícitas, como o crack, já bastante utilizado, e a cocaína, presente em alguns casos, porém mais rara por ser mais cara. 
A partir desses exemplos, fica claro que a categoria campo de possibilidades é imprescindivel para argumentar que "o projeto não é um fenômeno puramente interno, subjetivo, formula-se dentro de um campo de possibilidades" (VELHO, 2004, p. 27) marcado pelas condições estruturais e conjunturais em que vivemos, mas "há sempre uma combinação única de fatores psicológicos, sociais e históricos" (p. 28) atuando e influenciando as biografias, as subjetividades e os projetos. Nessa perspectiva, para Teixeira (1998, p. 15), "os atores sociais são criaturas e criadores da sociedade e da história e, sendo também seus intérpretes, vivem a permanente tensão entre escolhas e contingências, instituído e instituinte, factibilidade e possibilidade".

Sendo assim, quando falamos da juventude e seus projetos de vida, ponderar os elementos das condições estruturais e conjunturais que compõem o campo de possibilidades e as condições subjetivas que estão postas na dimensão individual é fundamental para não cairmos na tentação de assumir, por um lado, o discurso neoliberal que responsabiliza única e exclusivamente o sujeito pelo seu destino, levantando bandeiras do tipo "basta querer que você vai conseguir". Ou, em outro extremo, para não adotarmos uma posição pessimista e determinista do tipo "tem jeito não, quem nasceu para ser mula nunca chegará a cangalha”. Em outras palavras, se, por um lado, há quem atribua toda a responsabilidade dos projetos ao indivíduo, por outro, há quem o veja como um incapaz, um fracassado, que nunca vai ser alguém na vida. Ambas as posições desconsideram que as condições socioeconômicas em uma sociedade capitalista podem ser um comprometedor na elaboração dos projetos e que nem sempre basta querer. Tais condições podem, sim, produzir efeitos perversos, ceifar sonhos individuais e comprometer o próprio desenvolvimento social, por não oferecer igualdade de condições e oportunidades e por não proporcionar a todos o mesmo ponto de partida. ${ }^{1}$

1- Não entraremos aqui no debate acerca da tensão entre agência e estrutura. Assumimos, como defende Schutz (apud Peters, 2011), que não é possível desconsiderar a importância da ação individual e dos elementos
Um dos efeitos perversos de se fazer uma discussão sobre projetos sem problematizar essas duas dimensões de forma mais crítica pode ser percebido, no contexto atual, por exemplo, nos debates sobre as políticas de ações afirmativas. Em diversas ocasiões, presenciamos jovens discutindo o tema e se posicionando radicalmente contra as políticas de cotas nas universidades, utilizando como justificativa o discurso de que eles (por serem negros ou de escolas públicas) não são inferiores a ninguém e que, por isso, preferiam entrar na universidade "por seus próprios méritos". Isso evidencia a pouca reflexividade desses jovens acerca das condições estruturais em que viviam. Esse é o caso de Maria Antonia, uma jovem de 17 anos que acompanhamos na escola durante o terceiro ano do ensino médio e que acabara de entrar no curso de engenharia elétrica de uma universidade privada em Governador Valadares. Ela estava com muitas dificuldades para acompanhar o curso e assumia sozinha a responsabilidade por tal situação, justificando o fato de que estava pensando em desistir da faculdade:

[...] eu perdi o meu $1^{\circ}, 2^{\circ}$ e $3^{\circ}$ ano... Praticamente eu não estudava, eu não prestava atenção e depois eu não fiz cursinho e cheguei aqui ainda... Tipo, tô chegando e encarando um tanto de coisa difícil. [...] Se eu passar tranquila este período, vou continuar estudando; se não, se eu ficar em alguma matéria, eu pretendo parar, fazer um curso técnico e depois voltar para a faculdade. (Maria Antonia).

0 depoimento da Maria Antonia é semelhante ao de tantos outros que ouvimos em campo, de jovens que acreditavam que, se fossem mais esforçados, se estudassem mais, conseguiriam nota boa no Exame Nacional do Ensino Médio (ENEM), conseguiriam entrar em

subjetivos na elaboração dos projetos de vida. A história de cada de um de nós se faz com base no campo de possibilidades, mas também a partir dos desejos e intenções perseguidos pelos agentes, bem como das habilidades cognitivas que nos permitem agir sobre o nosso destino e não apenas ser produto das estruturas. 
uma boa universidade, muitas vezes sem ao menos questionar as próprias condições em que estudavam. Sem desconsiderar a necessidade e a importância do empenho e dedicação individual em qualquer projeto, queremos chamar atenção para o fato de que, quando um jovem de camada popular diz coisas do tipo "não passei no vestibular porque não estudei", ou "a culpa é minha, eu que sou burro mesmo", está assumindo sozinho uma responsabilidade que, afinal, é de toda a sociedade. E está também reproduzindo um discurso dominante que, além de criminalizar, responsabiliza a juventude por seus fracassos e desvios. No caso da Maria Antonia, ela enfrentou praticamente sozinha diversos desafios ao longo do ensino médio: a ausência dos pais que emigraram para os Estados Unidos quando ela tinha onze anos de idade; o preconceito da cidade pequena contra filhos de pais separados; o fato de viver na roça e ter de levantar de madrugada para sair para a escola e, por isso, perder muitas aulas no período das chuvas; o envolvimento com drogas lícitas ainda na puberdade. Mesmo assim, ela toma para si toda a responsabilidade pelo fato de não ter conseguido cursar o ensino médio como deveria, cuja consequência sente no ensino superior. Não se quer com isso dizer que o sujeito não tem sua parcela de responsabilidade sobre os destinos da sua vida. Quer-se, sim, defender a importância de o jovem conhecer a realidade em que está inserido para ser capaz de assumir um posicionamento crítico e autocrítico em relação ao campo de possibilidades e a si mesmo, como propõe Dayrell:

Quanto mais o jovem conhece a realidade em que se insere, compreende $o$ funcionamento da estrutura social com seus mecanismos de inclusão e exclusão e tem consciência dos limites e das possibilidades abertas pelo sistema na área em que queira atuar, maiores serão as suas possibilidades de elaborar e de implementar o seu projeto. As duas variáveis demandam espaços e tempos de experimentação e uma ação educativa que a possa orientar. (19_?, p. 03).

Nesse sentido, se, por um lado, uma leitura crítica do campo de possibilidades é necessária, também uma autorreflexão acerca da dimensão individual e subjetiva é fundamental. Assim, a discussão sobre identidade é central, pois, como afirma Dayrell (19_?, p. 2), “quanto mais o jovem se conhece, experimenta as suas potencialidades individuais, descobre o seu gosto, aquilo que sente prazer em fazer, maior será a sua capacidade de elaborar o seu projeto". Dessa forma, é importante não se perder de vista que, ao se falar da juventude, está se falando de uma etapa da vida em que os sujeitos estão vivenciando, de modo mais intenso, os processos de construção da identidade, de elaboração dos projetos de vida, de experimentação, de exercício da autonomia. Ademais, se há, por um lado, a necessidade de considerar o campo de possibilidades, também é importante levar em conta as características individuais, os desejos, as aptidões. Conhecer as estruturas externas e conhecer-se internamente é um exercício dialógico essencial na elaboração dos projetos de vida dos jovens. E, nesse exercício, as instituições socializadores têm um papel crucial. Caso contrário, os jovens podem se ver isolados, sós ou mesmo abandonados na elaboração dos seus projetos. No caso da Maria Antonia, acima citado, era exatamente assim que ela se sentia.

Por fim, nesse debate acerca da centralidade do sujeito e da tensão entre as possibilidades estruturais e individuais, importa salientar um aspecto fundamental, um mobilizador importante dos projetos, que é o desejo. Como já foi dito anteriormente, o projeto precisa ser assumido pelo sujeito. É por essa razão que, muitas vezes, vemos casos de jovens que nasceram em meios economicamente favorecidos ou em famílias que têm tradição em uma determinada área do sistema produtivo e que não seguem os caminhos trilhados pela família. Porque aquele não era o seu projeto. 
Portanto, desejo e determinação são os elementos que, aliados à biografia, à identidade e ao campo de possibilidades, servirão de alicerce para a concretização dos projetos de vida.

\section{Cada um com seu projeto ou por uma tipologia dos projetos de vida}

Diante da diversidade do grupo de informantes (diversidade de gênero, faixa etária, classe social e territorial), a pesquisa evidenciou que os projetos de vida dos jovens também são distintos. Nem todos organizam suas condutas da mesma forma, com os mesmos referenciais, a partir dos mesmos valores, das mesmas temporalidades, com o suporte das mesmas instituições e objetivando as mesmas metas. Isso porque, como afirma Velho (2004), os projetos não são estanques; ao contrário, são dinâmicos, podem mudar, transformar-se, assim como as próprias biografias humanas. A forma como os jovens explicitaram seus projetos, seja nos discursos cotidianos, seja nas entrevistas formais, levou-nos a categorizá-los de modo a identificar e explicitar as diversas possibilidades de compreensão de tais projetos. Importa ressaltar, no entanto, que tais categorias não são isoladas, impermeáveis, ou seja, pode ser que um mesmo projeto se encaixe em mais de uma categoria. Trataremos a seguir de apresentar e discutir a classificação dos tipos de projetos de vida, classificação essa feita a partir do grupo estudado.

Uma primeira categoria identificada refere-se a um grupo de jovens que elaboram seus projetos de forma mimética, ou seja, que tendem a imitar algo ou alguém que têm como referência positiva. Imitação não está sendo usada aqui no sentido de uma repetição mecânica, como poderia ser identificada no comportamento das formigas, por exemplo, mas no sentido que lhe dá o sociólogo francês Gabriel de Tarde, de uma imitação-refletida, ou uma imitação espontânea, como aquela das experiências sociais que adquirimos imitativamente, como a linguagem. Um exemplo de tal categoria é imitar um parente que se admira, um ídolo ou mesmo um conhecido que faz sucesso na comunidade, alguém que conquistou determinado status, que tem o respeito da sociedade, seja por meio da posição social ou da ocupação profissional. Nesses casos, os jovens, embora sem muita reflexão, sem levar em conta muitas vezes seu campo de possibilidades, desejam construir uma história de sucesso tendo como referência quem é sucesso para eles. Esse tipo de projeto é, em geral, influenciado por modismos, por tendências do mercado ou por notícias veiculadas pela mídia ou pelo boca a boca na pequena comunidade. Nesse modelo, os jovens se miram em alguém, olham e pensam: é lá que eu quero chegar. Muito comum entre os jovens que lançam mão desse tipo de projeto é planejar ser jogadores de futebol, como é o caso de Júnior, que justifica seu desejo referindo-se à fama, sucesso e glamour que envolve essa profissão:

Porque, tipo assim, o brasileiro é identificado com o futebol no mundo inteiro. Igual meus primos que tão lá na Inglaterra, todo mundo pergunta sobre o Ronaldinho Gaúcho, Robinho, Roberto Carlos... São, tipo assim, admirados, sabe? Nos quatro cantos do mundo e... é isso, a gente tem essa inspiração. É a fama... Igual hoje tem aí hoje o Neymar [...]. (Júnior, 18 anos).

A projeção e o status que se pode conquistar - e eles acreditam que é possível porque têm referências - é a grande mola propulsora de quem se projeta por meio da imitação, ou da negação, como veremos nos projetos de recusa. Ou seja, se alguém pode ser um modelo a ser imitado (no caso desse jovem, os grandes jogadores de futebol), também pode ser um modelo a ser recusado, como veremos adiante. Para o Júnior, o desejo de se tornar um jogador de futebol famoso, se era algo que estava no seu campo de possibilidades, esbarrava na questão do tempo, já que acabara de completar 18 anos e, para ser um jogador de 
futebol, é necessário começar a se preparar para a carreira ainda na infância. Esbarrava também em questões pessoais, subjetivas, já que não basta querer, não basta ter oportunidades para fazer os testes na idade certa - como ele relatou que chegou a fazer no Cruzeiro ${ }^{2}$. É preciso ter as características físicas, pessoais para se tornar um atleta e as habilidades para ser um jogador de futebol.

Em outro grupo, temos jovens com modelos de projetos que chamamos de hipomaníacos. Caracterizam-se pelo excesso de otimismo, euforia, mania de grandeza, projeções excessivas no futuro, desconhecimento do campo de possibilidades, quase uma fuga da realidade. Aqueles que se expressam no modo de projeto aqui definido como hipomaníaco, por vezes, parecem misturar realidade e fantasia, brincam com tudo que o futuro pode oferecer, já que, para estes, no futuro, tudo é possível. Eles se permitem fantasiar sem se preocupar com o campo de possibilidades, com possíveis limitações individuais ou com estratégias de realização dos seus projetos, como evidencia a fala dessa jovem:

Eu quero me dar o mundo, entendeu? Eu quero... Eu poderia ser política, policial, artista, tanto de pintar como de, de... Como é que fala? Artes cênicas ou... Entendeu? É isso tudo. Eu poderia pilotar um avião. Cê entende? Eu tenho vontade pra muita coisa, sabe? E, assim, eu acredito que eu vou conseguir fazer muita coisa do que eu quero, muita coisa. (Thalia, 18 anos).

Embora não cheguem a ser utópicos, já que não se trata de manifestar desejos completamente fora do campo de possibilidades, ou que dependam de mobilizar uma sociedade inteira para conseguir realizar, são projetos vagos, indefinidos, sem embasamento empírico que possa sustentá-los. São desejos imprecisos, caracterizados por promessas

\footnotetext{
2- Trata-se de time de futebol mineiro de grande proeminência.
}

desconexas, discursos vazios, caminhos sem rotas previamente estabelecidas. Esses sujeitos parecem saber que precisam pensar sobre seu futuro, que precisam começar a tomar as rédeas das suas próprias vidas, mas ainda não conseguem defınir nem o alvo nem a seta. São projetos comuns em quem faz planos para quando um dia ganhar na loteria, em quem tem sonhos ambiciosos ou almeja conseguir um status na sociedade por meio da conquista de bem materiais. Tais jovens querem tudo e manifestam tal desejo sem pensar muito nas estratégias para alcançá-los.

$\mathrm{Eu}$ quero! Eu tenho vontade! Eu posso! $\mathrm{Eu}$ pretendo! São todas frases comuns para expressar esse tipo de projetos. Nesse grupo, também se alocam jovens (em geral moças) cujo desejo de crescer, de melhorar de vida expressa-se pela busca do casamento dos sonhos, com um homem rico, para ter tudo que sempre sonharam, alguém que possa realizar todos os seus desejos de consumo. Nesses casos, a hipomania se apresenta no presente, com vistas a conquistar o futuro almejado. Algumas jovens endividam-se para comprar roupas caras, sapatos, acessórios, perfumes de marca para conquistar um namorado rico. 0 casamento, embora apareça mais como um projeto de recusa, para algumas jovens desta pesquisa, ainda é um meio de vida, na maioria das vezes, estimulado pelas mães, que inculcam nessas meninas a importância de conquistar um bom marido. Aqui, bom marido, muitas vezes, significa marido rico. Nesses casos, as jovens tendem a não refletir sobre as possibilidades reais de implementação do seu desejo, expressando uma falta de reflexão sobre a questão dos projetos.

Uma terceira categoria são os projetos estratégicos. Aqueles elaborados com base nesse modelo apresentam claramente alvo e seta, ou seja, os jovens sabem o que querem, evidenciam conhecimento suficiente do campo de possibilidades, de modo a avaliar e definir os fins e os meios possíveis para alcançá-los. Em alguns casos, mencionam um plano B e alternativas 
possíveis para lidar com os desafios da sociedade labiríntica em que estão crescendo. 0 tempo que caracteriza os sujeitos que organizam suas condutas futuras de modo estratégico é tanto o presente como o futuro, visto que, nas suas falas, fica evidente que eles não só se preocupam com o futuro, como se organizam no presente para alcançar os objetivos futuros. Tais jovens também evidenciam posicionamento em relação às questões enfrentadas no presente para organizar seus projetos e, embora para alguns deles as questões objetivas e subjetivas ainda se mostrem difusas nas análises sobre tais dificuldades, elas não são totalmente desconhecidas. Esse é o caso do jovem Antônio, que tinha 18 anos à época da pesquisa e sabia que queria estudar gastronomia, mas pensava em antes passar uma temporada nos Estados Unidos, junto à mãe:

Tipo, se eu for pra lá, eu vou rançar o couro, eu vou morrer de trabalhar, eu vou ganhar dinheiro, mas vou ter que trabalhar igual um condenado. Tipo, eu fico pensando isso também. Eu acho que eu não tenho precisão, tipo, minha família tem uma condição boa. Então, eu acho que não seria a hora de eu ir pra lá, ainda mais largar a escola, mas o negócio é esse. Porque, se eu for, eu vou ir no consulado e, tipo, tá quase garantido que eu vou legal. E meu dilema é esse, tipo, perder uma grande oportunidade, uma grande chance, porque eu acho que, se eu for no consulado e... apresentar minha proposta, falar o que eu pretendo fazer lá, eu acho que pode dar certo. (Antônio, 18 anos).

0 caso desse jovem é típico dos projetos estratégicos, em que os sujeitos se organizam baseados em informações, em análises da conjuntura, das condições pessoais e subjetivas, dos riscos, das possibilidades. Ele sabe que a migração irregular pode colocar sua própria vida em risco. Por isso, até cogita a possibilidade de sair do país, mas não se arriscaria emigrando em condições de ilegalidade. Ele também já tem claro que profissão quer seguir e sua escolha foi baseada nas suas habilidades e no que lhe dá prazer, a gastronomia:

E pretendo fazer faculdade ainda, de gastronomia. Eu gosto de cozinhar e eu acho que, tipo, eu acho que aqui ninguém nunca tentou isso e eu acho. [...] Eu gosto demais de gastronomia. Eu acho que... É muito chique aquele chapeuzim... [risos] $\mathrm{Eu}$ sei que comanda a cozinha. Eles... elabora os pratos e... Mas o negócio é começar de baixo. Primeiro, eu não vou começar como um chef de cozinha. Eu vou começar na cozinha, tipo, sendo um cozinheiro ou qualquer coisa, e depois que eu vou subindo, né... Pra depois montar meu próprio restaurante, qualquer coisa [...]. (Antônio, 18 anos).

0 passo a passo das ações, o planejamento organizado, a capacidade de crítica e autocrítica do campo de possibilidades é a marca dos sujeitos que organizam seus projetos de forma estratégica. Alvo e seta estão muito bem defınidos e a articulação entre passado, presente e futuro é evidente. Importa ressaltar, no entanto, que, no grupo pesquisado, os jovens classificados nesse tipo de projeto foram minoria.

Já os projetos de recusa são aqueles marcados pela lógica da negação veemente de algo que os jovens já conhecem, muitas vezes de experiências bem próximas ou até no seio familiar, as quais abjuram sob qualquer hipótese. Aqui a vivência pessoal é um elemento importante e experiências negativas que os afetam de alguma maneira são o que mais conta. Os tempos presente e futuro são contemplados, à medida que eles falam de projetos futuros sem perder de vista que tudo começa hoje, no tempo presente, e guarda uma relação intrínseca com o passado. 0 campo de possibilidades é bastante familiar e, por vezes, pode assustar por ser visto como determinista. Assim, os projetos se expressam pelo medo de 
fracassar em algo, porque há um membro da família que tentou e fracassou, ou pelo medo de se envolver com drogas, porque há casos na família e sabem que isso pode acontecer com eles. Há ainda a recusa da maternidade/ paternidade, por terem exemplos de colegas ou mesmo de familiares que foram pais/mães cedo ou de forma não planejada, o que eles veem como a última opção para suas vidas. Outro projeto recusado, nesse caso pelas meninas, é o de casar e se tornar dona de casa. Algumas são enfáticas em afırmar que querem qualquer coisa da vida, menos casar e ficar em casa cuidando de marido, filhos e casa, como fazem muitas mulheres em SGP: "Não quero os exemplos dele [o pai] pra mim, não. Encheu o mundo de filho e deixou aí pras mães cuidar" (Ana Flávia, 17 anos).

Em termos pessoais, outra recusa intensa que apareceu nas falas e no cotidiano desses jovens foi o desejo de não se envolver com drogas. Essa é uma mazela que ronda aquela pequena comunidade e assusta não só as famílias como os próprios jovens, que têm visto colegas se perderem em vícios como o crack e a cocaína, que eles achavam que só existiam em cidade grande. Assim, o envolvimento com drogas é algo muito presente nas falas do que recusam veementemente para suas vidas.

Em termos profissionais, os projetos de recusa são muito comuns em relação a algumas ocupações, como o trabalho na roça ou o trabalho doméstico, ou a algumas profissões, como a de professor:

Na área de educação, para mim, eu acho que não vai, que não ganha muito bem não, porque eu vejo as minhas tias, mesmo fazendo a área de educação para ser professor, chega uma época que não vai ter mais serviço para a área de professor. Aí eu penso em outra coisa pra mim. [...] Daqui uns dias, ninguém vai querer ser professor mais não, por causa do salário. (Daniel, 19 anos).

Embora ser professor seja algo bastante presente no campo de possibilidades desses jovens, eles avaliam a condição docente de modo bastante negativo, não vendo futuro na profissão nem vislumbrando vantagens no presente. Falam das dificuldades de lidar com crianças e jovens dentro da escola, apontam questões em suas próprias turmas, questões essas que, segundo eles, se fossem professores, não admitiriam. E recusam-se a ser professores pelas condições de trabalho no presente, trazendo exemplos que têm na família e a falta de perspectivas futuras.

Embora sem pensar apenas no futuro, mas analisando as condições presentes, o trabalho na roça (capinar, roçar, tombar lenha, cuidar de gado...) é recusado, sobretudo pelas condições desfavoráveis, por ser um trabalho pesado, por não ser valorizado social e financeiramente $e$ por se ter que acordar muito cedo e trabalhar no sol durante todo o dia:

Entrevistado $1^{3}$ : Tombar lenha e seguir o caminho dos meus irmãos na Padrão. É que eles trabalham em uma firma, a Padrão. Ai eles acordam quatro horas, três, três e meia e sai daqui quatro e meia, pra trabalhar. 0 único que tá escapando aqui é eu.

Entrevistado 4: Acho que trabalhar roçando. Igual o meu irmão mesmo, tem uma família grande, não estudou e está trabalhando roçando. Não quero essa vida pra mim não.

Algo que ficou marcado nessa categoria foi a recusa, quase sempre tendo em vista um membro da família, um amigo ou um parente próximo como referência, e a crença na escola e na educação como meio para sair, fugir desse futuro indesejado. Não é à toa que os próprios

3- Os informantes da pesquisa foram classificados em quatro grupos de acordo com o nível de participação: informantes gerais, informantes secundários, informantes primários e consultores. Desses, apenas os consultores foram apresentados com perfil completo na tese que origina este artigo. Os jovens identificados apenas como entrevistado integram o grupo dos informantes primários, formado por todos os estudantes que responderam ao questionário na escola e concordaram em participar da pesquisa. Eis o motivo pelo qual dois dos informantes são aqui apresentados como Entrevistado 1 e Entrevistado 4 e não com pseudônimos. 
pais e mães por vezes usavam, além das surras, a ameaça do trabalho pesado como estratégia para estimular os filhos a frequentarem a escola: "Se não quiser ir pra escola, cabo da enxada", ou ainda "ou a escola ou o cabo da vassoura". Esses eram os meios que algumas mães encontravam para colocar os filhos na linha quando eram chamadas para ouvir reclamações na escola.

Finalmente, foi possivel identificar sujeitos que não se encaixavam em nenhuma das categorias anteriores, por não vislumbrarem qualquer ação além do tempo presente. A esse grupo denominamos, inspirados em Boutinet, fora de projetos. Os sujeitos que identificamos como fora de projetos são aqueles que, dadas as condições de existência ou situações que estavam vivenciando, viam-se obrigados a concentrar todas as energias, sonhos e recursos no tempo presente, impossibilitando qualquer ação projetada. Assim como eles, Boutinet (2002) nos mostra que alguns grupos - como nas sociedades tradicionais ou mesmo os excluídos e marginalizados das sociedades capitalistas industriais -, dada a precariedade do modo de existência que os impede de antecipar, de vislumbrar um futuro, podem ser identificados como sem projeto ou fora de projeto. Assim, nesse contexto, foi possível identificar jovens em situação semelhante, que ainda não eram, naquele momento de suas vidas, capazes de se posicionar, de antecipar qualquer sonho, desejo ou meta para o futuro:

Eu não me vejo no futuro. Todo dia eu durmo achando que eu vou morrer [...]. Não me vejo no futuro não. Eu sou doida. $\mathrm{Na}$ mesma hora, quero fazer uma coisa, quero fazer outra. Na mesma hora, quero tentar aquilo, quero sumir no mundo, tenho futuro não. Vou ser um Zé Ninguém. (Ana Flávia, 17 anos).

Esse depoimento revela um sentimento de quem se sente sozinha, sem rumo, sem perspectiva. A ideia do Zé Ninguém diz do vazio que essa jovem sente. Ela se vê como sem importância, insignificante. Os sujeitos desse tipo de (não) projeto evitam lançar qualquer olhar sobre o futuro e, quando o fazem, demonstram desilusão e falta de expectativas para qualquer ação além do tempo presente. Isso pode ocorrer por diversas razões: as parcas possibilidades materiais em que vivem; a descrença que afeta a autoestima e a capacidade de antecipar qualquer conduta; ou ainda a falta de apoio por parte dos adultos para os sonhos e intenções que esses sujeitos possam tentar compartilhar. Esse último me parece ser o caso da jovem desse depoimento, que, em diversas ocasiões, reclamava que o pai não ligava para ela e a mãe não acreditava em nada que ela dizia que queria fazer.

É importante chamar atenção para essa categoria, já que esse sentimento pode ser típico de um momento ou uma fase da vida, mas pode prolongar-se e acabar por comprometer o desenvolvimento do sujeito. No caso dos jovens desta investigação, é possível que se trate de uma situação conjuntural, visto que, conforme demonstra o perfil, nenhum desses jovens que participaram como informantes podem ser identificados como pertencentes a algum grupo que possa ser rotulado como vulnerável à exclusão social. Malgrados os casos daqueles que passaram, ou passavam no momento da pesquisa, por situações de distanciamento geográfico dos pais ou de algum membro da família, ou mesmo que começaram a consumir bebida alcoólica ainda cedo, não é possível afirmar que se trata de um grupo em situação de risco social objetivo.

\section{Para concluir, o que eles desejam é "ser alguém na vida"}

0 que ser quando crescer? Há que ser? ${ }^{4}$ Se há que ser é porque não se é! Ou seria porque não se é o que gostariam que fôssemos? Ou porque não somos o que nós mesmos gostaríamos de

4 - No poema "Verbo Ser", Carlos Drummond de Andrade traz um questionamento ao qual poucos escapam desde tenra idade: "que vai ser quando crescer?". 
ser? No caso dos jovens aqui investigados, a expectativa que evidenciam sobre o ser, o devir na vida futura diz respeito tanto a perspectivas deles próprios quanto de outros (a família, a sociedade, o mundo). Como? Eles dizem (uns de forma mais objetiva, outros nem tanto) que o que desejam é ser alguém na vida. Como assim? Eles não são? Assim como no poema de Drummond, eles não têm um corpo, um jeito, um nome que os fazem alguém? Não têm uma vida? Ou precisariam crescer para ser alguém? Crescer e aparecer! Ser! Porque "Ser alguém na vida é você ser reconhecido na sociedade. Você desenvolver um serviço onde você pode ser conhecido. Ser conhecido, eu considero assim, é você ajudar realmente quem precisa, porque quem ajuda as pessoas é reconhecido na sociedade" (Netim, 19 anos).

A demanda por reconhecimento aparece em diversas ocasiões na fala desses jovens. 0 que eles pedem, afinal, quando reclamam que querem ser reconhecidos na sociedade? Para eles, ser alguém na vida significa ser reconhecido, ter o respeito da sociedade, ser enxergado e conhecido. Ser ouvido e respeitado. Ser valorizado. Enfım, sair da condição de invisibilidade, deixar de ser um “João Ninguém”, como nos falou certa vez um jovem morador da comunidade do Vinhático ${ }^{5}$. Para isso, eles têm claro que a inserção no sistema produtivo, por meio de uma atividade laboral que lhes garanta as condições necessárias de assumir-se como um membro autônomo da sociedade, é muito importante, mas é só o começo. Ou seja, se "a busca do projeto de vida parte de uma compreensão da constituição do sujeito mediante uma atividade laboral que lhe garanta a inserção social", como argumenta Dias (2009, p. 94), isso não é suficiente. Ser alguém na vida é muito mais do que conquistar um lugar no mercado de trabalho: é ter um lugar que lhe permita ser reconhecido como um membro da sociedade,

5- Vinhático é a mais pobre e mais populosa das comunidades rurais do município de SGP, de onde provêm $20 \%$ dos alunos matriculados no ensino médio. como um cidadão. Para os jovens sujeitos desta pesquisa, é evidente que falar em projetos de vida não significava apenas falar em profissão/ ocupação. E não poderia ser diferente. Afınal, projetar a vida não é apenas projetar a carreira. Para justificar essa afırmação, pensemos, por exemplo, em quando falamos em qualidade de vida. Nós estamos falando, na realidade, de uma série de fatores que contribuem para que tenhamos o que chamamos de uma vida com qualidade, como saúde, alimentação, trabalho, moradia, vida sexual, relacionamentos... Enfım, são diversas as dimensões da vida e o trabalho é apenas uma delas. ${ }^{6}$ Vejamos o depoimento de uma jovem que explicita bem essa ideia:

A gente quer estudar, a gente quer ser inteligente pra saber conversar com todo mundo, isso e tal. Mas a gente quer o quê? A gente não quer morar de aluguel, a gente quer ter uma casa. A gente não quer ver a nossa família morando na mesma casa com piso de cera. Cê tem que ralar o joelho pra poder passar aquela cera, ocê não quer. Ocê não quer uma casa pequena, que cê mal passa pela porta. Cê não quer sua família assim. (Thalia, 17 anos).

Esse e outros depoimentos deixam claro que esses jovens evidenciam diversas preocupações com relação ao futuro, questões que não dizem respeito apenas a que profissão seguir. Eles se questionam sobre questões do tipo: onde eu vou morar? Será que quero casar? Se quero, qual será a melhor idade para isso? Vou ter filhos? Nunca vou me envolver com drogas! Quero casar, mas não quero ser dona de casa! Será que vou conseguir ir para a universidade? Quero viajar, conhecer o mundo...

Enfim, eles elaboram seus projetos pensando em dimensões diversas e a vida profissional, para muitos deles, perpassa muitas

6- Partindo desse entendimento, consideramos que os estudos que tratam de projetos de vida sob a perspectiva profissional estão abordando apenas um aspecto dos projetos, já que tratam de apenas uma dimensão da vida humana. 
dessas dimensões. Talvez por isso muitas análises priorizem abordar os projetos de vida sob essa perspectiva. Nesse sentido, questões como casar, constituir família, discutir sobre o mundo das drogas, saber se posicionar sobre assuntos diversos como orientação sexual, religião, política, economia, continuar ou não os estudos depois do ensino médio, construir uma carreira acadêmica são todas potenciais matérias-primas para debates sobre projetos de vida e estiveram sempre presentes em nossas conversas. Os sujeitos demandam da escola falar sobre questões que os desafiam na vida, saber conversar.

Certa vez, uma jovem nos contou que a escola deveria ensiná-los "a entrar e sair". $\mathrm{Na}$ hora, não entendemos muito bem, mas seguimos conversando e ela explicou que, para vencer na vida, a pessoa precisa saber "se virar" em diferentes contextos. Isso para ela é saber entrar e sair, ou seja, saber como se comportar. Ela frisava que, como os pais eram da roça e desconheciam muita coisa importante que ela sabia que iria precisar pela vida fora dali, era isso que ela esperava da escola, além de aprender a ler e escrever. Essa crítica ao afastamento do currículo das suas realidades também foi apontada por jovens do Pará, em estudo de Leão, Dayrell e Reis (2011, p. 1082), que evidencia a "crítica dos jovens alunos a um currículo distante da sua realidade, pleiteando uma articulação maior entre os conteúdos e sua vida cotidiana”.

Portanto, o projeto de ser alguém na vida envolve diversos aspectos e demanda o conhecimento da realidade complexa na qual os jovens estão inseridos. Esses jovens demandam ser respeitados e admirados. Demandam não ser tratados como "jecas" quando precisarem "ganhar o mundo". Demandam ser independentes dos pais, dos cônjuges, enfim, almejam autonomia no mundo adulto. É por tudo isso que, para ser alguém na vida, não basta aprender uma profissão:

Ser alguém na vida é, tipo assim, é tá dependendo da gente mesmo, sem ficar, tipo assim, igual, a gente, eu dependo dos outros. Do jeito que eu tô aqui, eu dependo dos outros. Porque, se eu quero alguma coisa, tipo assim, igual eu, tipo assim, juntei, tipo casada, se eu preciso de alguma coisa, eu corro pra pessoa que tá do meu lado. (Thainá, 17 anos).

Analisando discursos pautados na ideia de ser alguém na vida para mães de uma comunidade na periferia carioca, Haanwinckel (2006) mostra que a projeção que aquelas mães fazem para o futuro dos filhos, traduzida na máxima "ser alguém na vida”, significa que desejam para a prole um futuro longe do que consideram o caminho errado, que pode envergonhá-las perante a comunidade. Elas desejam ver os filhos longe do mundo das drogas, do crime, longe de ser mães solteiras, enfim, desejam que os filhos "andem na linha" e que "não caiam na vida” (p. 105). Para essas mães, os caminhos que levarão seus filhos a conquistar essa "terra prometida" pautam-se nos pilares da educação e da inserção profissional. Os estudos também assumem centralidade no projeto de jovens mães de Belém do Pará analisadas por Pantoja (2003), para quem a maternidade precoce constitui um estímulo a mais na busca do projeto de ser alguém na vida.

Almejando identificar como historicamente as relações sociais de reconhecimento são desenvolvidas teoricamente, Mayer (2008) chama atenção para outros valores envolvidos nesse debate, como honra, respeito, reputação, estima social, moralidade e dignidade: “A noção de dignidade faz referência à esfera pública e às sociabilidades secundárias que a caracterizam" (2008, p. 40). Esse autor fala do reconhecimento ocorrido em âmbitos distintos da vida do sujeito, calcado nas relações primárias, no âmbito da família, desenvolvido na criança por meio da autoconfiança. Em outro âmbito, o reconhecimento é demandado a partir do exercício dos direitos sociais, que proporciona o reconhecimento público de todos os membros de uma sociedade que gozam de iguais direitos. 
Por fım, uma terceira dimensão trata do reconhecimento a partir das relações de solidariedade comunitárias, com vistas à conquista de objetivos comuns no grupo a que pertence e à agregação de valores. Ou seja, quando o jovem fala que não quer saber de envolvimento com drogas, está dizendo que não quer ser reconhecido na comunidade onde vive por esse motivo (como também pode acontecer o contrário, se o traficante for alguém valorizado/reconhecido/respeitado na comunidade, esse destino pode fazer parte dos projetos dos jovens).

Dessa forma, é possivel concordar com Dias (2009), para quem a vida em sociedade determina, de alguma maneira, quem somos, a forma como pensamos e orientamos nossos projetos de vida, de acordo com o papel que desejamos desempenhar nessa sociedade. Sendo assim, nossos projetos refletem nossos valores e os valores do grupo em que vivemos, como argumenta Machado (2004). Eles podem ser expressos de diferentes formas: para uns, mais explicitamente, para outros, de maneira mais vaga; para uns, a partir de uma referência próxima, para outros, como uma fuga de todo e qualquer modelo que tenham nas suas relações sociais. Foi isso que os jovens de SGP evidenciaram ao falar dos seus projetos de vida. E suas falas reforçam a necessidade de a escola, principalmente a de ensino médio, estar atenta a essa dimensão fundamental do humano, e em especial dos jovens, e funcionar como um suporte, contribuindo assim para a formação humana das novas gerações e para a construção dos projetos de vida dos jovens que ali estão.

\section{Referências}

ALVES, Maria Zenaide. Ser alguém na vida: condição juvenil e projetos de vida de jovens moradores de um município rural da região de Governador Valadares-MG. 2013. 213 f. Tese (Doutorado em Educação) - Faculdade de Educação da Universidade Federal de Minas Gerais - UFMG, Belo Horizonte, 2013.

BOUTINET, Jean-Claude. Antropologia do projeto. Porto Alegre: Artmed, 2002.

DAYRELL, Juarez Tarcisio. Por uma pedagogia da juventude. Belo Horizonte: [s. n.], [19_?]. Manuscrito.

DAYRELL, Juarez Tarcisio. Juventude, grupos de estilo e identidade. Educação em Revista, Belo Horizonte, n. 30, p. 25-38, dez. 1999.

DIAS, Maria Sara de Lima. Sentidos do trabalho e sua relação com o projeto de vida de universitários. 2009. 270 f. Tese (Doutorado em Psicologia) - Centro de Filosofia e Ciências Humanas da Universidade Federal de Santa Catarina - UFSC, Florianópolis, 2009.

FUSCO, Wilson. Redes sociais na migração internacional: 0 caso de Governador Valadares. 2000. 120 f. Dissertação (Mestrado em Sociologia) - Instituto de Filosofia e Ciências Humanas da Universidade Estadual de Campinas - Unicamp, Campinas, 2000.

HAANWINCKEL, Bárbara Zilli. Como "ser alguém na vida"? Caminhos e planos de vida de mães para jovens moradores do Morro Azul na cidade do Rio de Janeiro: uma análise sociocultural. 2006. Dissertação (Mestrado) - Universidade Federal do Rio de Janeiro - UFRJ, Rio de Janeiro, 2006.

IPEA-BRASIL. Migração interna no Brasil, 2010. Comunicado IPEA, Brasília, n. 61. Disponível em: < http://www.ipea.gov.br>. Acesso em: 2014.

LEÃO, Geraldo; DAYRELL, Juarez Tarcisio; REIS, Juliana. Juventude, projetos de vida e ensino médio. Educação e Sociedade, Campinas, v. 32, n. 117, p. 1067-1084, out./dez. 2011. Disponível em: <http://www.cedes.unicamp.br>. Acesso em: 15 jul. 2012.

MACHADO, Nilson José. Educação: projetos e valores. São Paulo: Escrituras, 2004. 
MARGOLIS, Maxine L. Little Brazil. An ethnography of Brazilian immigrants in New York City. Princeton: Princeton University Press, 1994.

MASSEY, Douglas et al. Theories of international migration: a review and appraisal. Population and Development Review, v. 19, n. 3, p. 431-466, set. 1993.

MAYER, Ricardo. A lógica do respeito: notas críticas em torno do conceito de reconhecimento. Latitude, Maceió, v. 35, n. 2, p. 34-67, 2008.

PANTOJA, Ana Lídia Nauar. "Ser alguém na vida": uma análise sócio-antropológica da gravidez/maternidade na adolescência, em Belém do Pará, Brasil. Cadernos de Saúde Pública, Rio de Janeiro, v. 19, Sup. 2, p. S335-S343, 2003.

PETERS, Gabriel. Admirável senso comum? Agência e estrutura na sociologia fenomenológica. Ciências Sociais Unisinos, São Leopoldo, v. 47, n. 1, p. 85-97, jan./abr. 2011.

SIQUEIRA, Sueli. Migrantes e empreendedorismo na micro-região de Governador Valadares: sonhos e frustrações no retorno. 2006. 200 f. Tese (Doutorado em Ciências Humanas) - Faculdade de Filosofia e Ciências Humanas da Universidade Federal de Minas Gerais - UFMG, Belo Horizonte, 2006.

SOARES, Weber. Da metáfora à substância: redes sociais, redes migratórias e migração nacional e internacional em Valadares e Ipatinga. 2002. 344 f. Tese (Doutorado) - Centro de Desenvolvimento e Planejamento Regional da Faculdade de Ciências Econômicas da Universidade Federal de Minas Gerais - UFMG, Belo Horizonte, 2002.

SPRANGER, Eduard. Psicologia da juventude. 1. ed. Rio de Janeiro: Bloch, 1970.

TEIXEIRA, Inês Assunção de Castro. Tempos enredados: teias da condição professor. 1998. Tese (Doutorado) - Faculdade de Educação da Universidade Federal de Minas Gerais - UFMG, Belo Horizonte, 1998.

VEIGA, José Eli da. Cidades imaginárias: o Brasil é menos urbano do que se calcula. Campinas: Autores Associados, 2003. 304p.

VELHO, Gilberto. Projeto e metamorfose: antropologia das sociedades complexas. Rio de Janeiro: Jorge Zahar, 2003.

VELHO, Gilberto. Individualismo e cultura: notas para uma antropologia da sociedade contemporânea. Rio de Janeiro: Jorge Zahar, 2004.

Recebido em: 22.03.2014

Aprovado em: 25.11.2014

Maria Zenaide Alves é doutora em educação pela Universidade Federal de Minas Gerais (UFMG), com estágio sanduíche na Columbia University. É professora na Universidade Federal de Goiás, campus de Catalão (UFG) e coordenadora do Núcleo de Extensão e Pesquisa em Educação e Desenvolvimento do Campo (Nepcampo).

Juarez Tarcisio Dayrell é doutor em educação pela Universidade de São Paulo e pós-doutor pelo Instituto de Ciências Sociais da Universidade de Lisboa. Atualmente, é professor associado da Universidade Federal de Minas Gerais (UFMG) e pesquisador do Conselho Nacional de Desenvolvimento Científico e Tecnológico (CNPq). É fundador e integrante do Observatório da Juventude da UFMG (www.observatoriodajuventude.ufmg.br). 